\title{
ANVIL PRODUCTIVITIES OF TROPICAL DEEP CONVECTIVE CLUSTERS AND THEIR REGIONAL DIFFERENCES
}

\author{
Min Deng ${ }^{1 *}$, Gerald G. Mace ${ }^{2}$, Zhien Wang ${ }^{1}$, \\ ${ }^{1}$ Department of Atmospheric Science, University of Wyoming, Laramie, Wyoming, 820072, USA, *mdeng2@uwyo.edu \\ ${ }^{2}$ University of Utah, Salt lake City, USA
}

\begin{abstract}
Tropical deep convection's intensity and their anvil productivity are investigated and compared among 8 climatological regions with 4-year collocated and combined CloudSat and CALIPSO data. For all 8 regions, the convective clusters become deeper, while they become wider and tend to be composed of multiple rainy cores. Among 8 regions, convective clusters at the same scale over EP and AT tend to have less but wider rainy cores than those at WP, MA and IO, while those over AF, IO, MA and AM tend to have higher cloud top than those over ocean. For convective clusters less than $300 \mathrm{~km}$ wide over $\mathrm{AF}$ and MA, the rainy cores pump more ice mass of larger particles to the mid- and upper troposphere in strong updrafts.

The total anvil clouds detrained from convection counts for 0.4 to 0.8 of the cluster horizontal scale, 0.2 to 0.6 of the cluster cross section volume, and 0.05 to 0.20 of the cluster ice mass, depending on the cluster scales and height. There are two main detrainment layers. When the convective clusters is less than about $100 \mathrm{~km}$, the anvil clouds are mainly detrained at about $6-8 \mathrm{~km}$ with a spreading ratio (ratio of maximum cluster width to convection rainy core width) less than 1.5. When convective clusters becomes $100 \mathrm{~km}$ or wider, it reaches the dominate detrainment layer at about $12 \mathrm{~km}$, the detrainment index increase from 2 to more 6 . Among 8 regions, convection clusters in MA produce the most anvil volume fraction. The more the ice mass is pumped upward in the anvil clouds till clusters are about $500 \mathrm{~km}$ wider. Nevertheless, the anvil ice mass pumped above $15 \mathrm{~km}$ is less than $0.1 \%$ of the total ice mass in the convective cluster.
\end{abstract}

\section{INTRODUCTION}

The tri-modal characteristics of tropical convection (Johnson et al. 1999) indicates prominent stable layers that exist over the Pacific warm pool and the tropical eastern Atlantic, which are associated with tri-modal distributions of divergence, cloud detrainment, and fractional cloudiness. Deep convection with a precipitation region $100 \mathrm{~km}$ in dimension is called a mesoscale convective system (MCS) (Zipser 1969, 1977; Houze 1977; Leary and Houze 1979; Houze, 2004). Sometimes frequent MCSs tend be merged or connected by their massive stratiform anvil clouds to form super clusters or mesoscale convective complex (MCC; Maddox 1980) with a scale of thousands of kilometers wide. Hydrometers produced in convective updrafts of an MCS are transported into the large mesoscale stratiform precipitating regions, where they fall out slowly or can be detrained into the environment or left aloft as stratiform anvil (Gamache and Houze 1983; Pfister et al. 2001; Mace et al. 2006; and Mullendore et al. 2009). Convective cells are capable of supplying ice to an anvil with large areal extent and thickness, which is determined by the strength and duration of the active convective updrafts as well as by the large-scale vertical motion, environmental wind shear, and moisture profile. These factors also determine how long the anvil is present after convection has ceased (Mapes and Zuidema, 1996; Mace et al. 2006; Cetrone and Houze 2009). The intensity, life cycle, and diurnal cycle of tropical deep convection have been long investigated with passive sensors and TRMM (Fu et al 1990; Chen and Houze 1997; Cetrone J. and Houze 2009; Nesbittt and. Zipser, 2002; Futyan and Del Genio 2007; Liu et al 2008) and carry a large geographic variation. For example, the diurnal fluctuation of deep convection is significant over tropical landmass. The convection over land such as central Africa, Indonesia and South America tends to overshoot tropopause frequently.

The anvil extent and its microphysical properties are related closely to the heating profiles and water vapor transport, hence it is crucial for global momentum budgets and radiative budgets, as highlighted in recent studies (e.g., Hartmann et al. 1992; Mace et al. 2011; and Klein et al. 2013). From ISCCP C2 climatology, Chou et al. (1999), Houze (1989), and Machado and Rossow (1993) showed that high cirrus fraction tends to increase strongly as deep cloud top temperature drops, which is referred as the cirrus-detrainment-temperature (CDT) relation. Such a finding stimulated further investigations about climate feedbacks associated with cirrus clouds (Ramanathan et al. 1989, 1991; Chou et al. 1999; Lindsen et al. 2002; Hartmann et al. 2002; Stephens 2005). However, besides of the horizontal extent, the vertical structure and microphysical properties of anvil clouds are very important information for further cirrus cloud radiative 3$\mathrm{D}$ effect study, modeling evaluation and further climate feedback study (Klein and Jacob 1999).

The CloudSat satellite and the other A-Train satellites provide a new dimension of space-based observations of clouds and precipitation (Stephens et al 2010). Given the high sensitivity of Cloud Profiling Radar (CPR) onboard of CloudSat to sense the non-raining anvil, it has widely used to study tropical convection anvil productivity in terms of reflectivity and scales (Cetrone and Houze 2009, Yuan and Houze, 2010, 2011, 2013; Bacmeister and Stephens 2011).

The Cloud-Aerosol Lidar with Orthogonal Polarization (CALIOP) onboard of CALIPSO satellite can observe the cold top of deep convection and optically thin 
cirrus layers in the upper troposphere. Cirrus clouds at 14$16 \mathrm{~km}$ tend to be too tenuous to be detected by CloudSat, whose occurrence can be as high as $\sim 60 \%$ (Sassen and Wang 2008).

The combination of these two active sensors provides the full cross section of deep convection system, which has been used to study the tropical convection evolution during the MJO cycle (Del Genio et al 2012). In this study we will utilize the combined and collocated rangeresolved CPR and CALIOP data to characterize the horizontal and vertical structure of tropical convection clusters and their composite anvil productivities among the convective clusters in terms of horizontal scale, cross section volume. Moreover, we take advantages of ice cloud properties retrieval from the CloudSat 2C-ICE product to provide the unprecedented ice mass transport among the convection. Regional differences are compared among 8 climatological regions.

\section{DATA AND METHOD}

In this study we use the combined and collocated CloudSat and CALIPSO data during 2007-2010. The CALIOP and CPR provide very valuable complementary observations to cover clouds from those optically thin cirrus in the upper troposphere to precipitation near the surface. Several CloudSat standard products are used here. Cloud geometrical profile from combined CPR and CALIOP measurements (2B-GEOPROF-lidar; Mace et al., 2009) provides the cloud boundaries. Cloud scenario classification from combined $\mathrm{CPR}$ and CALIOP measurements (2B-CLDCLASS-Lidar, Sassen and Wang 2011) provides cloud phase (liquid, ice, or mixed-phase) determination for each cloud layers and classify it as one of eight basic cloud types, so that downstream retrieval algorithms or assumptions can be applied to the conditions for which they are considered valid.

Ice cloud microphysical properties are from CloudSat $2 \mathrm{C}$-ICE product, which is a synergetic ice cloud retrieval from combining the CPR and the CALIOP measurements using a variational method to provide the profiles of extinction coefficient, ice water content (IWC) and effective radius (re) for ice particles (Deng et al., 2010, 2013). Deep convection clouds are identified as mixedphase cloud layer by 2B-CLDCLASS-Lidar, where CALIOP signal is quickly attenuated at the cold top. Since CPR is sensitive to large ice particles due to the $\sim 6$ power law relation between reflectivity and size, 2C-ICE assumes that CPR mainly detects ice particles above the melting layer by neglecting the possible super-cool water. Therefore, 2C-ICE provides ice properties in both anvil clouds as well as the ice particles in the deep convective core.

The ECMWF-AUX product is created by the GenericAUX Interpolate-to-Reference algorithm to provide the temperature, press and relative humidity $(\mathrm{RH})$.

We use a cluster based approach to analyze the convection clusters along the A-Train track as Bacmeister and Stephens (2011). First the convection cluster (Figure 1 ) is defined as: a group of radar and/or lidar detected and

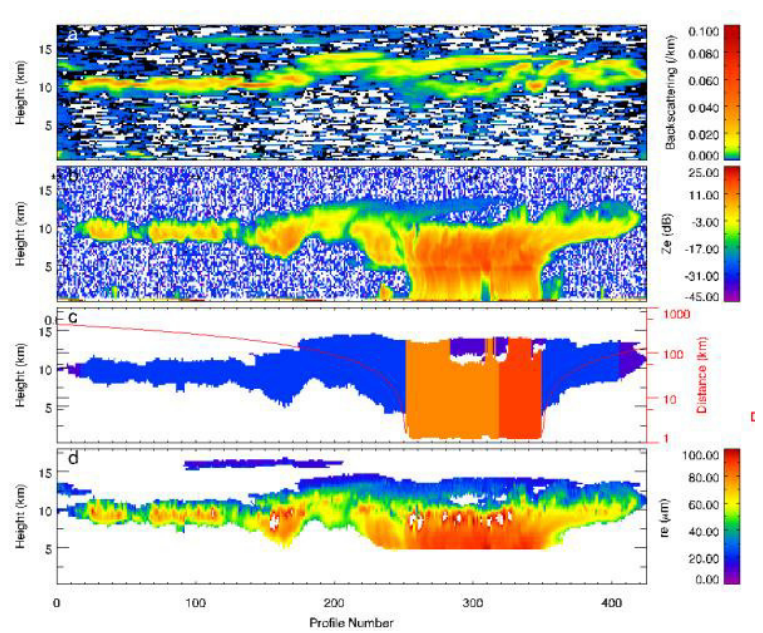

Figure 1 a) CALIOP backscattering, b) CPR Ze, c) convective cluster with cloud classification from CLDCLASS_lidar, and d) effective radius (re) from $2 C$ ICE. The color coded cloud types are Deep convection (Dc in red), Cumulonimbus (Ns in orange), Altostratus (As in blue) and high cirrus (Cs in purple).

horizontally or vertically connected cloud layers in GEOPROF-lidar that contains deep convective clouds classified by 2B-CLDCLASS lidar. Only the deep convective clusters with cluster top higher than about $\sim 9$ $\mathrm{km}$ are selected in this study, while convection in Bacmeister and Stephens (2011) includes those clusters with cloud top less than $10 \mathrm{~km}$. Without using the collocated MODIS imagery, it is hard to find the horizontal 2D structure. However, as long as the convection cloud system in this study do not possess high and systematic anisotropy relative to the A-train track, the sampling pattern of A-Train should not produce major statistic biases in the spatial statistics examined here. Other studies using cloud photographs and MODIS imagery have indicated a mean cloud horizontal aspect ratio of around 2 with no systematic orientation of features (Benner and Curry, 1998; Bacmeister and Stephens 2011).

For each convective cluster (Figure 1), the convective cluster rainy core is first identified and composed of the deep convection, nimbostratus and cumulus congenstus clouds as classified in the CLDCLASS_lidar product with a width $W_{c b}$. Low level cumulus clouds are discriminated from this deep convective cluster. While the anvil clouds are composed of the connected altostratus and high clouds in the convective clusters. The second thin cirrus layer above $15 \mathrm{~km}$ is also discriminated as possible, which may not be directly associated with deep convection. The corresponding horizontal span, volume, and ice mass of the cluster and its anvil in every 480 meter are noted as $W_{\text {clu }}\left(z_{i}\right) \quad V_{\text {clu }}\left(z_{i}\right), \quad I W C_{\text {clu }}\left(z_{i}\right)$ and $W_{\text {anvil }}\left(z_{i}\right), \quad V_{\text {anvil }}\left(z_{i}\right)$, $I W C_{\text {anvil }}\left(z_{i}\right)$ respectively. The maximum horizontal span or scale and vertical depth of the convective cluster are noted as $W_{\text {cluster }}$ and $D$, respectively. The cross-section area ( 
$\left.\sum_{i} W_{c l u}\left(z_{i}\right) \times \Delta z\right)$ is referred as the cluster total volume $(V)$ as in Bacmeister and Stephens (2011) to avoid confusion with the cloud horizontal area.

In this study, we define total anvil horizontal fraction, anvil volume ratio, and anvil ice mass ratio to the total of the cluster for each cluster. Then the clusters are sorted by the effective width $W_{\text {eff }}$ (defined as the ratio of the cluster volume and maximum cloud depth: $W_{e f f}=V / D$ ) rather than $W_{\text {cluster }}$ to produce composite results about convection clusters and their anvil productivity, avoiding the possible contamination of extensive tropospause clouds.

\section{RESULT ABOUT CONVECTIVE CLUSTER}

Figure 2 shows the global distribution of identified convective clusters from combined CPR and CALIOP data during 2007-2010 in a 10 x 5 degree grid resolution. ITCZ, South America, and Atlantic are the most deep convection active regions. There is a clear tendency that the most convective clusters over land or over oceans adjacent to land, in locations favors storms motion from land to ocean. This pattern is very similar to the TRMM monthly mean rainfall in Liu et al (2008). The geographical pattern of tropical deep convective cluster occurrence is well correlated with the sea surface temperature (SST) pattern. Eight tropical climatological regions are selected to represent their unique tropical convective regimes, which are similar to those in Yuan et al. (2010): Tropical Africa (AF), Indian Ocean (IO), Maritime Continent (MA), Western Pacific (WP), Eastern Pacific (EP), Southern Pacific (SP), Central American (AM), and Atlantic (AT). IO and MA are the hottest regions, while $\mathrm{EP}$ and $\mathrm{AT}$ are coldest among the 8 regions. Given the snapshots of CloudSat and CALIPSO, their observation at certain regions may be biased to certain convection development stage. The number distribution of convective clusters and probability density functions of convective cluster scales are shown in Figure 3.We can see that there is a decent sample of convection clusters for all regions, given the geographic variation for 8 regions. Convection in IO and MA, followed by AM, WP and SP, tends to be connected by the extensive anvil to form super clusters (connected MCSs or MCC) larger than $1000 \mathrm{~km}$. Convection at EP and AT are very similar with a narrow scale range between 100 and $1000 \mathrm{~km}$.

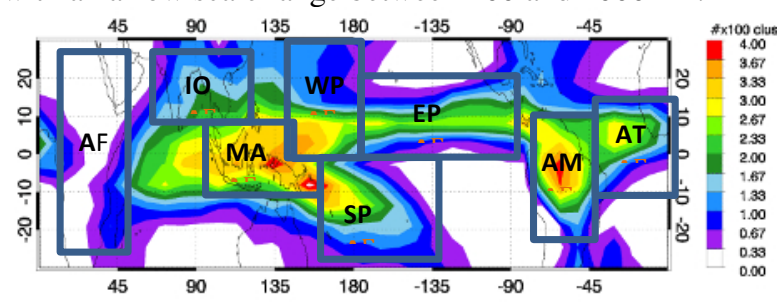

Figure 2 Maps of (a) total number of tropical convective clusters identified with CloudSat and CALIPSO There are eight regions boxed for the regional anvil cloud study: Tropical Africa (AF), Indian Ocean (IO), Maritime Continent (MA), Western Pacific (WP), Eastern Pacific (EP), Southern Pacific (SP), Central American (AM), and Atlantic (AT)

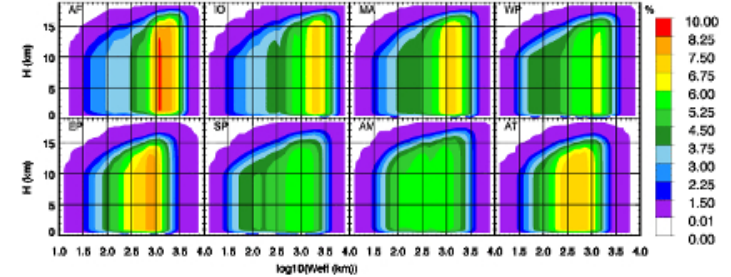

Figure 3 Composite convective clusters probable density function of occurrence by height as a function of $W_{\text {eff }}$ for the 8 regions

Convection at $\mathrm{AF}$ has an outstanding scale peak at about $1000 \mathrm{~km}$, while convection in AM is almost evenly distributed between $10 \mathrm{~km}$ to $1000 \mathrm{~km}$. This is consistent with Nesbitt and Zipser (2002) that AF is revealed for its major share of moderate intense storms although IO and MA have the most extensive events. We can see that for all 8 regions, the convective clusters tend to shoot higher as their horizontal scale increases. The cluster top height increases from $12 \mathrm{~km}$ to more than $16 \mathrm{~km}$, cluster top temperature decreases from $230 \mathrm{~K}$ to $190 \mathrm{~K}$. At the same $W_{\text {eff }}$ scale, the convective clusters over AF, IO, MA and AM tend to have higher cloud top than those over ocean. The composite mean cross section volume by height is shown Figure 3 for the 8 regions. First, we can see that the volume increases at all height as the cluster $W_{\text {eff }}$ increases. Second, cross section volume has two prominent peaks vertically. The first is above the melting layer or at 6-8 $\mathrm{km}$. This peak becomes less obvious as the $W_{\text {eff }}$ increases. The second peak is above $10 \mathrm{~km}$ and become prominent as the $W_{\text {eff }}$ increases. The corresponding peak height increases as $W_{\text {eff }}$ increases. This trend would not be fully detected without the CALIPSO CALIOP observations.

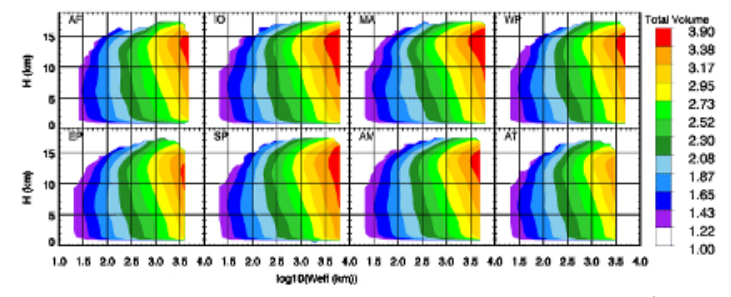

Figure 4 Composite cross section volumes $\left(\mathrm{km}^{2}\right.$ in logarithm) by height as a function of $W_{\text {eff }}$ for the 8 regions: a) from combined CloudSat and CALIOP observations

\section{DISCUSSION AND CONCLUSION}

We found out that for all regions, when the convective clusters become wider, the convective clusters become deeper. The clusters tend to be composed of multiple rainy cores and each core becomes wider. Among the 8 regions, convections in $\mathrm{EP}$ and $\mathrm{AT}$ tend have less but wide rainy cores, while WP, MA and IO tend to have more but narrow rainy cores. For the convections at the same scale, AF, IO, MA and AM tend to have higher cloud top than those over ocean. 
Without counting the stratiform rain, the anvil clouds detrained from convection count for 0.4 to 0.8 of the cluster horizontal fraction, 0.2 to 0.6 of the cluster cross section volume, and 0.05 to 0.20 of the cluster ice mass, depending on the cluster scales.

The vertical dependence of anvil productivity shows that there are two main detrainment layers, which is consistent with the tri-mode theory in Johnson et al. (1999). When the convection cluster is less than $100 \mathrm{~km}$, the anvil cloud is mainly detrained at about $6-8 \mathrm{~km}$ with a detrainment index or anvil spreading ratio (ratio of maximum cluster width over convection rainy core, Yuan and Houze 2010; Bacmeister and Stephens 2011) less than 2.5. This detrainment layer is related to the stable layer near $0^{\circ} \mathrm{C}$, which inhibit cloud growth, and enhance the detrainment just above it for those congestus clouds. The existence of a volume peak and anvil volume ratio near this level at times of organization of convection on the MCS $(\sim 100 \mathrm{~km})$ scale suggests that processes that contribute to enhanced detrainment near that level may also contribute to restricting cloud growth to that level. When for vigorous convection clusters, undiluted or less diluted updrafts in the convection keep pump hydrometers up till it meets the higher stable level, which causes other enhanced detrainment layer between 10 and $16 \mathrm{~km}$ with the detainment index increasing from 2.5 to more than 6 and anvil horizontal fraction quickly increase from 0.3 to more than 0.8. Even the convective cluster with $\mathrm{W}_{\text {eff }}$ larger than $500 \mathrm{~km}$ can reach $16 \mathrm{~km}$, the anvil detrainment in volumes maximize at about $14 \mathrm{~km}$, which is about 1-2 $\mathrm{km}$ lower than the cluster top.

ACKNOWLEDGEMENT: The A-Train data are acquired from CloudSat Data center at Colorado State University. We'd like to thank the engineers, technicians, and scientists for the high-quality and well documented data. This work is supped by NASA. We also appreciate the anonymous reviewers for their suggestions and comments.

\section{REFERENCES}

Bacmeister, J. T., and G. L. Stephens (2011), Spatial statistics of likely convective clouds in CloudSat data, J. Geophys. Res., 116, D04104, doi:10.1029/2010JD014444

Chen, S. S., and R. A. Houze Jr., 1997: Diurnal variation and lifecycle of deep convective systems over the Pacific warm pool. Quart. J. Roy. Meteor. Soc.,123, 357-388.

Chou C. J. D. Neelin (1999) Cirrus detrainment-temperature feedback. Geophysical Research Letter, 26, 1295-1298.

Cetrone J. and R. A. Houze Jr. 2009: anvil clouds of tropical mesoscale convective systems in monsoon regions. Quart. J. Roy. Meteor. Soc. 135: 305-317

Deng, M., G. G. Mace, Z. Wang, and H. Okamoto, 2010: Tropical Composition, Cloud and Climate Coupling Experiment validation for cirrus cloud profiling retrieval using CloudSat radar and CALIPSO lidar, J. Geophys. Res., 115, D00J15, doi:10.1029/2009JD013104 (6)

Futyan J, Del Genio A. 2007. Deep convective system evolution over Africa and the tropical Atlantic. , J. Clim 20: 5041-5060
Fu, R., A. D. Del Genio, and B. Rossow, 1990: Behavior of deep convective clouds in the tropical Pacific deduced from IPSSP radiance, , J. Clim, 3, 1129-1152. 1990.

Gamache, J. F., and R. A. Houze (1983), Water budget of a mesoscale convective system in the tropics, J. Atmos. Sci., 40(7), 1835 - 1850.

Hartmann, D. L., M. E. Ockert-Bell, and M. L. Michelsen (1992), The effect of cloud type on Earth's energy balance: Global analysis,, J. Clim., 5, $1281-1304$.

Houze, R. A., Jr., 1977: Structure and dynamics of a tropical squall line system observed during GATE. Mon. Wea. Rev.,105, 15401567.

- 2004: Mesoscale convective systems. Rev. Geophys., 42, 43

Johnson R. H. T. M. Rickenbach. S. A. Rutledge, P. E. Ciesieski, and W. H. Schubert, 1999: Trimodal characteristics of Tropical convection. J. Clim, 12, 2397- 2418.

Klein S. and C. Jakob 1999 Validation and sensitivities of frontal clouds simulated by the ECMWF model. Monthly weather review, 127, 2514-2531

Klein, S. A., Y. Zhang, M. D. Zelinka, R. Pincus, J. Boyle, and P. J. Gleckler (2013), Are climate model simulations of clouds improving? An evaluation using the ISCCP simulator, J. Geophys. Res. Atmos.,118, 1329-1342, doi:10.1002/jgrd.50141.

Leary, C. A., and R. A. Houze (1979), Melting and evaporation of hydrometeors in precipitation from the anvil clouds of deep tropical convection, J. Atmos. Sci., 36(4), 669-679

Liu, C. T., E. J. Zipser, D. J. Cecil, S. W. Nesbitt, and S. Sherwood, 2008: A cloud and precipitation feature database from nine years of TRMM observations. J. Appl. Meteor. Climatol.,47, 2712-2728.

Lindzen, R. S., M.-D. Chou, and A. Y. Hou (2002), Comments on "No evidence for iris", Bull. Am. Meteorol. Soc., 83, 1345 - 1348.

Maddox RA. 1980. Mesoscale convective complexes. Bull. Am. Meteorol. Soc.61: 1374-1387.Machado, L. A. T., and W. B. Rossow, Structural characteristics and radiative properties of tropical cloud clusters, Mon. Weather Rev., 121, 3234-3260, 1993.

Mapes, B. E., and P. Zuidema, 1996: Radiative-dynamical consequences of dry tongues in the tropical troposphere. $J$. Atmos.Sci., 53,620-638.

Mace GG, Deng M, Soden B, Zipser E. 2006. Association of tropical cirrus in the $10-15-\mathrm{km}$ layer with deep convective sources: An observational study combining millimeter radar data and satellite derived trajectories. J. Atmos. Sci. 63: 480-503.

Mullendore, G. L., A. J. Homann, K. Bevers, and C. Schumacher (2009), Radar reflectivity as a proxy for convective mass transport, J. Geophys. Res., 114, D16103, doi:10.1029/2008JD0114

Nesbittt S. W. E. Zipser, 2002: the diurnal cycle of rainfall and connective intensity according to three years of TRMM measurement. , J. Clim, 16, 1456-1475

Pfister, L., et al., Aircraft observations of thin cirrus clouds near the tropical tropopause, J. Geophys. Res., 106, 9765 - 9786, 2001.

Ramanathan, V., R. D. Cess, E. F. Harrison, P. Minnis, B. R. Barkstrom, E. Ahmad, and D. Hartmann, Cloud-radiative forcing and climate: results from the earth radiation budget experiment, Science 243, 57-63, 1989

Stephens, G. L. (2005), Cloud feedbacks in the climate system: A critical review, J. Clim., 18, $237-273$

Yuan J. and R. A. Houze Jr. 2010: Global variability of mesoscale convective system anvil structure from A-train satellite data , $J$. Clim, 23, 5864-5888

Yuan J. and R. A. Houze Jr. 2011: vertical structure of anvil clouds of tropical mesoscale convective systems observed by CloudSat. J. Atmos. Sci. 68, 1653-1674.

Yuan J. and R. A. Houze Jr. 2013: Deep convective systems observed by A-Train in the tropical Indo-Pacific regions affected by the MJO. J. Atmos. Sci. 70, 465-486

Zipser, E. J., 1969: The role of organized unsaturated downdrafts in the structure and rapid decay of an equatorial disturbance. J. Appl. Meteor., 8,799-814 